\title{
BMJ Open Reinventing the community hospital: a retrospective population-based cohort study of a natural experiment using register data
}

\author{
Jayson O Swanson, Terje P Hagen
}

To cite: Swanson J0, Hagen TP. Reinventing the community hospital: a retrospective populationbased cohort study of a natural experiment using register data. BMJ Open 2016;6:e012892.

doi:10.1136/bmjopen-2016012892

- Prepublication history for this paper is available online. To view these files please visit the journal online (http://dx.doi.org/10.1136/ bmjopen-2016-012892).

Received 31 May 2016 Revised 12 November 2016 Accepted 18 November 2016

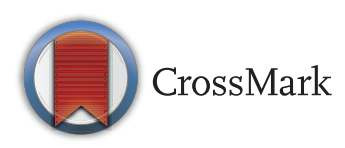

Department of Health Economics and Health Management, Institute of Health and Society, University of Oslo, Oslo, Norway

Correspondence to Jayson 0 Swanson; j.o.swanson@medisin.uio.no

\section{ABSTRACT}

Objectives: To investigate whether implementation of municipal acute bed units (MAUs) resulting from the Norwegian Coordination Reform (2012) was associated with reductions in hospital admissions, particularly for the elderly.

Design: A municipality-based retrospective comparative cohort study using monthly populationbased registry data analysed with fixed-effects log-log regressions.

Setting: Norwegian municipalities and hospitals. Population: All patients admitted to secondary hospital care in Norway between 2010 and 2014, excluding psychiatric admissions, with additional focus on admission type and elderly age subgroups.

Main outcome measures: Monthly admission rates in total and by age group for all patients, patients admitted with acute conditions and with acute conditions at internal medicine departments.

Results: The introduction of MAUs was associated with a small yet significant overall negative effect on hospital admissions. The reduction in all admissions was significant for the entire population $(-1.2 \%, 95 \%$ $\mathrm{Cl}-2.0 \%$ to $-0.0 \%$ ) and slightly stronger for those aged 80 years and above $(-1.9 \%, 95 \% \mathrm{Cl}-3.0 \%$ to $-1.0 \%$ ). The more detailed analysis of the elderly population aged 80 years and above revealed that effects were affected by the institutional characteristics of the MAUs. The significant effects ranged between $-1.6 \%$ and $-8.6 \%$, depending on the availability of physicians on duty at the MAUs, the MAUs location or combinations thereof.

Conclusions: Introduction of MAUs following implementation of the Norwegian Coordination Reform in 2012 was associated with a significant reduction in hospital admissions primarily for the elderly. Our findings suggest that this type of intermediate care is a viable option in an effort to alleviate the burden on hospitals by reducing the acute secondary care admission volume. Further examinations focused on cost-effectiveness, health status of patients, number of patients treated at the MAUs and comparing other intermediate care alternatives would all add important perspectives to the issue.

\section{Strengths and limitations of this study}

- To the best of our knowledge, this is the first study to explicitly address the effect of intermediate care alternatives on general hospital admissions.

- Implementation of municipal care units (municipal acute bed units, MAUs) at different points in time in different municipalities made it uniquely possible to isolate the effects of MAUs on the number of hospital admissions.

- The narrow time period after the reform's implementation that induced MAU services may bias the results.

- Endogeneity concerns exist since the municipalities self-select their implementation points.

\section{INTRODUCTION}

Units like the Norwegian municipal acute bed units (MAUs) have recently generated international attention following a statement by the head of the British National Health Service (NHS), Simon Stevens. In his first interviews in early 2014, Stevens signalled that small local hospitals should be the focus of expanded and improved services in the community to allow elderly patients to be treated locally. ${ }^{12}$ The Norwegian MAUs were implemented as part of the Coordination Reform from 2012 with the explicit goal of treating patients 'who otherwise would have been admitted to hospitals' and with 'equally good or better quality' for selected patient groups than what a general hospital would offer. $^{3}$

MAUs were organised as part of municipal health services together with general practitioners (GPs), local emergency services, longterm care services and other social care services. ${ }^{4}$ Patients admitted to MAUs are those who have been assessed by a GP, usually at a local emergency service, and identified as 
needing close follow-up by nurses or primary physicians. MAUs are mainly regarded as a service for either stable patients with a known acute primary diagnosis that can be evaluated and treated by primary care methods or patients whose treatment needs to be re-evaluated and adjusted. Typical MAU patients were expected to be elderly with pneumonia, infections (especially urinary tract), gastroenteritis, chronic obstructive pulmonary disease, diabetes, heart failure or dehydration.

Services like MAUs have been operating in a few remote municipalities in Norway since the early 1980s. ${ }^{5}{ }^{6}$ Introduction of a earmarked grant from the Norwegian central government to the municipalities in 2012, aimed at stimulating investments in MAUs, led to a rapid increase in the number of units. By the end of 2014, the first MAUs in the recent wave had been in operation for $2 \frac{1}{2}$ years, and just over half of the municipalities, representing $64.8 \%$ of the population, were covered by MAUs. Beginning in 2016, MAUs are mandated by the central government organised either as a municipal service covering one municipality or as intermunicipal co-operations covering two or more (often smaller) municipalities. ${ }^{3}$ Several studies have evaluated the effects of intermediate care units on postacute care. $^{7-9}$ To the best of our knowledge, no studies have explicitly addressed the effect of intermediate care alternatives, like MAUs, on hospital admissions. Consequently, we examined the effects of implementation of MAUs on the number of hospital admissions, with special focus on elderly age groups using data from 2 years before and 3 years after introduction of the Norwegian Coordination Reform. Information on the exact starting dates and the spread of the implementation of MAUs over time makes it feasible to isolate the statistical effects of MAUs on the number of hospital admissions.

\section{METHODS}

Data and study population

We included patients admitted to hospital in Norway between 1 January 2010 and 31 December 2014, excluding psychiatric hospitals. In total, this accounted for 5.3 million admissions. After analysing all admissions, we focused on two subgroups: below 80 years of age (4.5 million admissions) and 80 years of age and above (800 000 admissions). We then conducted a more detailed analysis focusing on those 80 years and above classified by specific admission type (acute admissions and acute admissions at internal medicine departments) and institutional characteristics of the MAUs. Data on admissions were obtained from the Norwegian National Patient Register (NPR).

We acquired annual municipal data from Statistics Norway's KOSTRA database covering all Norwegian municipalities from 2010 through 2014. This database included variables describing the municipal supply of services such as number of nursing home beds, number of GPs, GP contracted hours per week in nursing homes and variables describing the demand for services such as death rates and population size, both in total and for specific age groups. We included all municipalities, except for four which were amalgamated into two during the study period $(\mathrm{N}=426)$.

Monthly descriptive data for each MAU was obtained via telephone interviews administered in two rounds taking place in summer 2014 and summer 2015. Data were linked based on municipality number, year and month followed by linear interpolation to estimate the monthly values for municipal demand and supply data that were reported annually. This gave us a data set with panel structure.

\section{Outcomes}

Numbers of admissions for different types of services and age groups were allocated to the municipalities based on the patient's place of residence, summed and standardised per 1000 inhabitants. Based on the aim of MAUs, we hypothesised that the estimated effects were greater for elderly patients, patients in internal medicine departments and those admitted acutely (contrary to the entire patient population, patients in surgical departments and elective admissions, respectively).

\section{Independent variables}

MAU access, the main predictor variable, was defined as a binary variable-we assigned municipalities a value of 1 from the month when the first patient was treated at the MAU. Before that point, and for all municipalities without MAU services, a value of 0 was assigned. In separate analyses, we distinguished between municipalities based on how they had established MAUs: alone, in cooperation with others as a host or in cooperation with others as a guest. As for the MAU variable, we coded these variables (MAU-ALONE, MAU-HOST and MAU-VISITOR) as dummies and assigned a value of 1 from the month when the first patient was treated, and 0 otherwise.

On the basis of initial analyses, we included three variables describing the supply side: number of beds in nursing homes, number of GPs and number of contracted hours per week for GPs in institutions (nursing homes). We modelled the demand for municipal services using the following variables: the population divided into age groups $(<80$ and 80 years and above), the total number of inhabitants and the number of deaths within the population. The number of deaths captures increased care usage and expenditure during the final period of life. ${ }^{10-12}$ Both supply and demand side independent variables were normalised per 1000 inhabitants. Variables indicating MAU service provision and location (physician services available 24 hours a day, 7 days a week and those MAUs operating in conjunction with municipal emergency departments) were analysed in combination with operating service agreement classifications (alone or cooperating as a host or 
visitor). These were included in the final analyses as interaction terms with all possible combinations of MAU location, physician services provided and operating agreements.

\section{Analysis}

Since the number and composition of patients in MAUs are currently unknown, we applied linear regression models to estimate the effects of the introduction of MAUs on the demand for hospital services. Our statistical set-up originated from a standard demand model framework adapted to analyse the public sector. ${ }^{13-15}$ We assumed that the municipalities chose between MAUs and hospital care based on local demand and supply factor information. A simplified version of the model can be written as:

$$
\begin{aligned}
& \log \mathrm{H}_{\mathrm{mt}}=\alpha+\beta_{\mathrm{s}} \log \mathrm{S}_{\mathrm{mt}}+\beta_{\mathrm{D}} \log \mathrm{D}_{\mathrm{mt}} \\
& \quad+\beta_{\mathrm{MAU}} \mathrm{MAU}_{\mathrm{mt}}+\mathrm{f}_{\mathrm{m}}+\beta_{\mathrm{Month}} \text { Month }_{\mathrm{mt}}+\mathrm{u}_{\mathrm{mt}}
\end{aligned}
$$

where $\log \mathrm{H}_{\mathrm{mt}}$ were the natural logarithms of variables describing demand for hospital services from each municipality $m$ at time $t, S$ was a vector of municipal supply variables such as nursing homes and $\mathrm{D}$ was a vector of municipal demand factors such as the age composition of the population. MAU is defined above. The $\alpha$ is a constant term.
The municipal demand (D) and supply (S) variables, as well as MAU, were specified for each of the municipalities $(m)$ for each month $(t)$. The variable $f$ is fixed effects for municipalities, Month a seasonal adjuster and $\mathrm{u}$ an error term. The use of fixed effects in data with a panel structure allowed us to control for data heterogeneity, both observed and unobserved, and focus on the variable of interest. ${ }^{16}$ For example, fixed effects for municipalities give us the within estimator of the MAU variable. ${ }^{17}$ All variables except for the dummy variables were $\log$ transformed.

We regarded all variables except MAU as exogenous. MAU might have elements of endogeneity as municipalities with high admission rates have a slightly stronger incentive to implement MAUs than municipalities with lower admission rates. Primarily, we handled this endogeneity problem via municipal fixed effects. ${ }^{16}$

Norwegian municipalities differ considerably in population size with the smallest having $<300$ inhabitants and the largest having more than 640000 (2014). The median municipality has $\sim 5000$ inhabitants and the average population size is slightly below 12000 , demonstrating that the majority of municipalities are smaller than the average. To make the analyses generalisable to the Norwegian population, all of the models were weighted by municipal populations (population weights). We ran all analyses with robust SEs using Stata V.13.1.

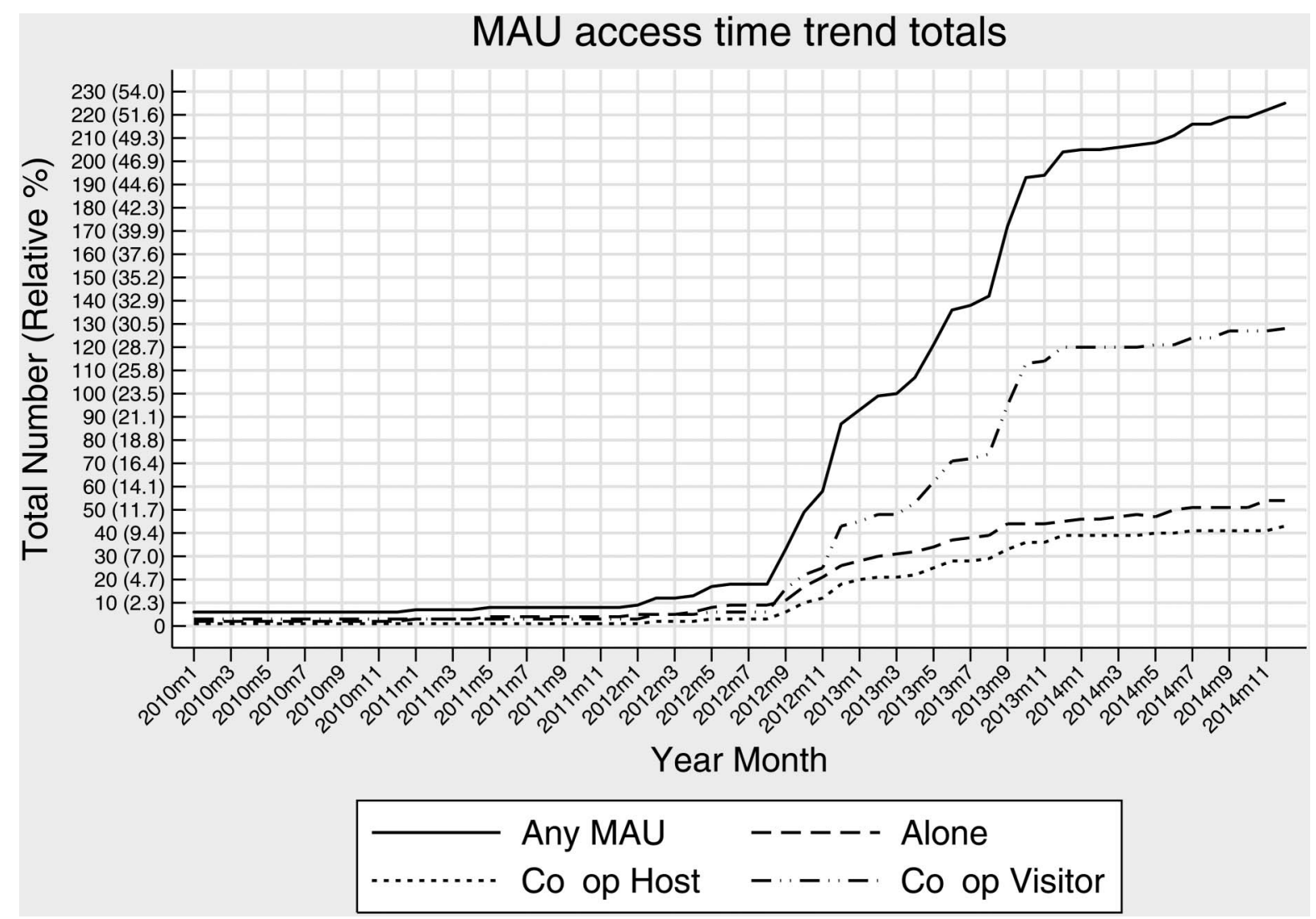

Figure 1 Number of municipalities with acute unit access and differentiated by access type (January 2010 to December 2014 ). Registration based on month when first patient was treated in the MAU. MAU, municipal acute bed unit. 


\section{Sensitivity analyses}

We performed two sensitivity analyses. First, and as an alternative to the fixed-effects approach, we followed Dranove and Cone ${ }^{18}$ and conducted a two-step analysis to account for a possible 'catch-up' effect among the municipalities. This effect characterises the possible instance where those municipalities with the largest number of acute admissions, compared with what is expected from their service and patient characteristics before the reform, are more likely to be the first to introduce MAU services. In the first step, we assessed the demand for hospitals during the autumn of 2011, the point at which municipalities were made aware of the upcoming grant from the central government, based on a set-up similar to that used in the main analyses. In the second step, we included the residual from the first step as an independent variable in the original model for acute internal medicine admissions for those patients aged 80 years and above. The residual will capture excess use of hospitals after adjustment for demographic and other relevant factors.
In the second sensitivity analysis, we estimated the models grouping municipalities based on population size where we segmented them above and below the median population value. We also evaluated the independent variables for multicollinearity.

\section{RESULTS}

\section{Descriptive statistics}

By the end of 2014, 221 (51.8\%) municipalities had implemented MAUs (figure 1).

Reviewing descriptive statistics for the dependent variables (table 1), we see a general reduction in the median admission rates when comparing the period before the reform to the period after the reform. The log-transformed dependent variables used in the regression analyses indicate the same pattern with regard to mean values.

Considering the independent variables (table 2), there were increases in all median values after the reform except for slight decreases in the median population aged 80 years and above, recorded death rates and nursing home bed numbers per 1000 inhabitants.

Table 1 Descriptive statistics for dependent variables, before (2010-2011) and after (2012-2014) implementation of the Coordination Reform

\begin{tabular}{|c|c|c|c|c|c|c|c|c|c|c|}
\hline \multirow[b]{2}{*}{ Variable name } & \multicolumn{5}{|c|}{ Pre-reform (2010-2011) } & \multicolumn{5}{|c|}{ Postreform (2012-2014) } \\
\hline & Mean & SD & Minimum & Median & Maximum & Mean & SD & Minimum & Median & Maximum \\
\hline Total admissions* & 15.86 & 3.96 & 2.70 & 15.38 & 41.54 & 15.69 & 3.90 & 2.34 & 15.21 & 99.92 \\
\hline $\begin{array}{l}\text { Acute internal medicine } \\
\text { admissions* }\end{array}$ & 8.98 & 2.79 & 0.00 & 8.68 & 28.58 & 8.74 & 2.81 & 0.00 & 8.47 & 90.71 \\
\hline Total admissions $<80$ years ${ }^{*}$ & 13.27 & 3.45 & 1.49 & 12.90 & 41.54 & 13.14 & 3.38 & 0.00 & 12.79 & 91.63 \\
\hline Total admissions $80+$ years ${ }^{\star}$ & 2.59 & 1.39 & 0.00 & 2.36 & 13.55 & 2.55 & 1.41 & 0.00 & 2.31 & 24.08 \\
\hline Acute admissions $80+$ years ${ }^{*}$ & 2.03 & 1.20 & 0.00 & 1.85 & 11.01 & 1.96 & 1.19 & 0.00 & 1.78 & 14.45 \\
\hline $\begin{array}{l}\text { Acute internal medicine } \\
\text { admissions } 80+\text { years }^{*}\end{array}$ & 1.74 & 1.10 & 0.00 & 1.57 & 10.28 & 1.69 & 1.08 & 0.00 & 1.52 & 14.45 \\
\hline $\begin{array}{l}\text { Log total admissions } \\
<80 \text { years* }\end{array}$ & 2.63 & 0.24 & 0.91 & 2.63 & 3.75 & 2.62 & 0.24 & 0.00 & 2.62 & 4.53 \\
\hline $\begin{array}{l}\text { Log acute admissions } \\
<80 \text { years }{ }^{*}\end{array}$ & 2.20 & 0.28 & 0.00 & 2.22 & 3.44 & 2.17 & 0.29 & 0.00 & 2.19 & 4.45 \\
\hline $\begin{array}{l}\text { Log acute internal medicine } \\
\text { Admissions }<80 \text { years }{ }^{*}\end{array}$ & 2.07 & 0.30 & 0.00 & 2.08 & 3.33 & 2.04 & 0.30 & 0.00 & 2.07 & 4.43 \\
\hline $\begin{array}{l}\text { Log total admissions } \\
80+\text { years }^{\star}\end{array}$ & 1.06 & 0.38 & 0.00 & 1.07 & 2.43 & 1.03 & 0.38 & 0.00 & 1.03 & 3.22 \\
\hline $\begin{array}{l}\text { Log acute admissions } \\
80+\text { years }^{*}\end{array}$ & 0.88 & 0.38 & 0.00 & 0.89 & 2.39 & 0.85 & 0.37 & 0.00 & 0.85 & 2.74 \\
\hline $\begin{array}{l}\text { Log acute internal medicine } \\
\text { admissions } 80+\text { years }^{\star}\end{array}$ & 0.80 & 0.37 & 0.00 & 0.80 & 2.25 & 0.76 & 0.37 & 0.00 & 0.76 & 2.74 \\
\hline
\end{tabular}




\section{Regression results}

Our analyses indicate that implementation of MAUs decreased the number of admissions generally. Introduction of MAUs corresponded to a small significant negative effect of $-1.2 \% \quad(\mathrm{p}<0.01)$ on admissions for the entire population (table 3). Stratifying admissions above and below 80 years of age garnered both a slightly stronger (above 80 years) and a slightly weaker (below 80 years) effect, $-1.9 \% \quad(\mathrm{p}<0.01)$ and $-1.0 \%$ $(\mathrm{p}<0.05)$, respectively (table 3$)$. The other demand variables yield reasonable effects. A $1 \%$ increase in the death rate was associated with an increase in the number of total admissions by $0.05 \% \quad(\mathrm{p}<0.01)$, total admissions for those below 80 years by $0.04 \% \quad(\mathrm{p}=0.02)$ and total admissions for those aged 80 years and above by $0.07 \%(\mathrm{p}<0.01$; table 3$)$. Additionally, a $1 \%$ increase in the population aged above 80 years was associated with an increase in the number of admissions for those aged above 80 years by $0.73 \% \quad(\mathrm{p}<0.01)$, but did not have a statistically significant effect when considering admissions for those aged below 80 years or for all admissions combined (table 3). For the variables describing the municipal supply of services, effects were small and in most cases not significant.

Focusing on the analysis of acute and acute internal medicine admissions for those aged 80 years and above, and combined with variables describing operating service agreements, location of the MAU and service variables, in the form of interaction terms, provided additional detail to our findings (table 4). The general analysis for those aged 80 years and above, independently evaluating acute admissions and acute internal medicine admissions, showed that they were both affected by the introduction of an MAU with changes of $-1.7 \%$

Table 2 Descriptive statistics for independent variables, before (2010-2011) and after (2012-2014) implementation of the Coordination Reform

\begin{tabular}{|c|c|c|c|c|c|c|c|c|c|c|}
\hline \multirow[b]{2}{*}{ Variable name } & \multicolumn{5}{|c|}{ Pre-reform (2010-2011) } & \multicolumn{5}{|c|}{ Postreform (2012-2014) } \\
\hline & Mean & SD & Minimum & Med & Maximum & Mean & SD & Minimum & Med & Maximum \\
\hline $\begin{array}{l}\text { Population aged } \\
<80 \text { years* }^{*}\end{array}$ & 944.88 & 15.36 & 900.71 & 945.44 & 980.13 & 946.29 & 14.64 & 900.83 & 946.63 & 979.74 \\
\hline $\begin{array}{l}\text { Population aged } 80+ \\
\text { years* }\end{array}$ & 55.12 & 15.36 & 19.87 & 54.56 & 99.29 & 53.71 & 14.64 & 20.26 & 53.37 & 99.17 \\
\hline $\begin{array}{l}\text { Number of deaths* } \\
\text { (death rate) }\end{array}$ & 10.31 & 3.09 & 0.00 & 9.98 & 26.20 & 10.11 & 3.06 & 3.17 & 9.77 & 26.36 \\
\hline $\begin{array}{l}\text { Beds in nursing } \\
\text { homes* (nursing home } \\
\text { beds) }\end{array}$ & 11.38 & 5.56 & 1.57 & 10.48 & 38.46 & 11.35 & 5.78 & 0.19 & 10.42 & 40.63 \\
\hline Number of GPs* (GPs) & 1.02 & 0.43 & 0.38 & 0.92 & 5.24 & 1.06 & 0.46 & 0.38 & 0.97 & 5.40 \\
\hline $\begin{array}{l}\text { GP contracted hours } \\
\text { per week in institutions }\end{array}$ & 3.69 & 2.11 & 0.00 & 3.23 & 20.27 & 4.27 & 2.33 & 0.00 & 3.84 & 19.65 \\
\hline Population per 1000 & 11.61 & 34.96 & 0.22 & 4.56 & 613.29 & 11.98 & 36.57 & 0.21 & 4.61 & 647.68 \\
\hline Any MAU access & 0.02 & 0.13 & 0.00 & 0.00 & 1.00 & 0.30 & 0.46 & 0.00 & 0.00 & 1.00 \\
\hline MAU co-operation host & 0.00 & 0.06 & 0.00 & 0.00 & 1.00 & 0.06 & 0.23 & 0.00 & 0.00 & 1.00 \\
\hline MAU alone & 0.01 & 0.10 & 0.00 & 0.00 & 1.00 & 0.08 & 0.26 & 0.00 & 0.00 & 1.00 \\
\hline $\begin{array}{l}\text { MAU co-operation } \\
\text { visitor }\end{array}$ & 0.01 & 0.10 & 0.00 & 0.00 & 1.00 & 0.16 & 0.37 & 0.00 & 0.00 & 1.00 \\
\hline $\begin{array}{l}\text { Log population aged } \\
<80 \text { years* }\end{array}$ & 6.85 & 0.02 & 6.80 & 6.85 & 6.89 & 6.85 & 0.02 & 6.80 & 6.85 & 6.89 \\
\hline $\begin{array}{l}\text { Log population aged } 80 \\
+ \text { years* }\end{array}$ & 3.99 & 0.29 & 3.04 & 4.02 & 4.61 & 3.96 & 0.29 & 3.06 & 4.00 & 4.61 \\
\hline $\begin{array}{l}\text { Log number of deaths* } \\
\text { (death rate) }\end{array}$ & 2.39 & 0.28 & 0.00 & 2.40 & 3.30 & 2.37 & 0.27 & 1.43 & 2.38 & 3.31 \\
\hline $\begin{array}{l}\text { Log beds in nursing } \\
\text { homes* (nursing home } \\
\text { beds) }\end{array}$ & 2.42 & 0.45 & 0.94 & 2.44 & 3.68 & 2.41 & 0.46 & 0.17 & 2.43 & 3.73 \\
\hline $\begin{array}{l}\text { Log number of GPs* } \\
\text { (GPs) }\end{array}$ & 0.69 & 0.17 & 0.32 & 0.65 & 1.83 & 0.70 & 0.18 & 0.32 & 0.68 & 1.86 \\
\hline $\begin{array}{l}\text { Log GP contracted } \\
\text { hours per week in } \\
\text { institutions* }\end{array}$ & 1.46 & 0.41 & 0.00 & 1.44 & 3.06 & 1.58 & 0.40 & 0.00 & 1.58 & 3.03 \\
\hline $\begin{array}{l}\text { Log population } \\
\text { per } 1000\end{array}$ & 1.87 & 0.96 & 0.20 & 1.71 & 6.42 & 1.88 & 0.97 & 0.19 & 1.72 & 6.47 \\
\hline
\end{tabular}

${ }^{\star}$ Per 1000 inhabitants.

$\mathrm{GP}$, general practitioner; MAU, municipal acute bed unit. 
$(\mathrm{p}=0.01)$ and $-1.6 \% \quad(\mathrm{p}=0.01)$, respectively (table 4$)$. There was an overall effect of MAUs with a physician on duty 24 hours a day, 7 days a week, which was generally far stronger than the general effects reported above. For municipalities operating MAUs as hosts providing physician services 24 hours a day, 7 days a week, there were significant changes in admission rates of $-8.1 \%$ $(p<0.01)$ for acute admissions and $-8.6 \% \quad(p<0.01)$ for acute admissions at internal medicine departments (table 4). The remaining interaction effects characterising services and location for MAU hosts were nonsignificant, indicating that having physicians on duty is a crucial factor. For municipalities using MAUs as visitors, the effect ranged from $-3.8 \%(\mathrm{p}<0.01)$ to $-6.6 \%$ $(\mathrm{p}=0.02)$ for acute admissions and from $-4.0 \%(\mathrm{p}<0.01)$ to $-6.5 \% \quad(p=0.02)$ for admissions to acute internal medicine departments depending on the availability of physician services and MAU location or combinations thereof. Also, for this group of municipalities, the results indicate that MAUs without either around-the-clock physician services or operating in conjunction with an local emergency service had non-significant effects. Similar to those municipalities hosting MAUs, for municipalities operating an MAU alone which provides physician services 24 hours a day, 7 days a week, there were significant changes in admission rates of $-1.7 \%$ $(\mathrm{p}=0.03)$ for acute admissions and $-1.7 \%(\mathrm{p}=0.02)$ for acute admissions at internal medicine departments (table 4). Unlike for host municipalities, these effects, although significant, were slightly weaker than the general effect of $-1.9 \% \quad(p<0.01)$ from table 3 . The other interaction effects characterising services and location for MAUs operating alone were less stable and non-significant.

\section{Sensitivity analyses}

When the residual was included as an independent variable to capture the 'catch-up' effect, the residual took on statistically significant positive estimates. Controlling for the municipalities' initial admission levels, however, did not alter our main results as the effects of the variables describing MAUs were largely unchanged. Estimating the regressions for municipalities categorised by population (above and below the median) did not change the main results. It did, however, indicate that the majority of significant effects are observed among those municipalities with medium-sized to large-sized populations, which include those with $\sim>5000$ inhabitants.

\section{DISCUSSION}

\section{Principal findings}

Implementation of MAUs initiated as part of the Norwegian Coordination Reform led to a significant reduction in hospital admissions of $-1.2 \%$. The effects were strongest for the age group above 80 years with a point estimate of $-1.9 \%$. The more detailed analysis presented for this age group further indicates that the organisations of MAUs are important. Our final models capturing interactions between operating service agreements, the location of the MAU and service variables provide indications that these factors, particularly the constant availability of physician services, influence the MAU's effect on hospital admissions. The effects of having an MAU with physicians on duty $24 / 7$ were up to around $8 \%$ for acute admissions and acute admissions at internal medicine departments for the highest age group. MAUs without physicians on duty $24 / 7$ or that

Table 3 Regression results for hospital admissions 2010-2014, including total population, above 80 years and below 80 years, with municipal fixed effects (log-log models)

\begin{tabular}{|c|c|c|c|c|c|c|}
\hline \multirow[b]{2}{*}{ Variables } & \multicolumn{2}{|l|}{ All } & \multicolumn{2}{|l|}{$\leq 80$ years } & \multicolumn{2}{|l|}{$80 \pm$ years } \\
\hline & Estimate $(95 \% \mathrm{Cl})$ & p Value & Estimate (95\% Cl) & p Value & Estimate (95\% Cl) & p Value \\
\hline $\begin{array}{l}\text { Population aged } \\
<80 \text { years }\end{array}$ & $-2.543(-8.82$ to 3.74$)$ & 0.43 & $-1.890(-8.25$ to 4.47$)$ & 0.56 & $-0.568(-9.79$ to 8.65$)$ & 0.90 \\
\hline $\begin{array}{l}\text { Population aged } \\
80+\text { years }\end{array}$ & $0.076(-0.29$ to 0.45$)$ & 0.69 & $-0.041(-0.40$ to 0.32$)$ & 0.83 & $0.733(0.26$ to 1.21$)$ & 0.00 \\
\hline Death rate & 0.047 (0.02 to 0.08$)$ & 0.00 & 0.038 (0.01 to 0.07$)$ & 0.02 & 0.070 (0.03 to 0.11$)$ & 0.00 \\
\hline $\begin{array}{l}\text { Nursing home } \\
\text { beds }\end{array}$ & 0.032 (0.00 to 0.06$)$ & 0.04 & 0.036 (0.01 to 0.07$)$ & 0.02 & $0.003(-0.05$ to 0.06$)$ & 0.90 \\
\hline GPs & $0.021(-0.05$ to 0.10$)$ & 0.59 & $0.002(-0.07$ to 0.08$)$ & 0.95 & $0.120(-0.00$ to 0.24$)$ & 0.06 \\
\hline GPs man-years & $-0.047(-0.21$ to 0.11$)$ & 0.57 & $-0.023(-0.18$ to 0.14$)$ & 0.78 & $-0.158(-0.41$ to 0.10$)$ & 0.23 \\
\hline Total population & $0.045(-0.18$ to 0.27$)$ & 0.69 & $-0.037(-0.27$ to 0.19$)$ & 0.75 & 0.413 (0.18 to 0.64$)$ & 0.00 \\
\hline $\begin{array}{l}\text { Any MAU } \\
\text { access }\end{array}$ & $-0.012(-0.02$ to -0.00$)$ & 0.00 & $-0.010(-0.02$ to -0.00$)$ & 0.02 & $-0.019(-0.03$ to -0.01$)$ & 0.00 \\
\hline constant & $19.632(-24.94$ to 64.20$)$ & 0.39 & $15.746(-29.29$ to 60.78$)$ & 0.49 & $0.634(-64.56$ to 65.83$)$ & 0.98 \\
\hline Observations & 24763 & & 24763 & & 24763 & \\
\hline $\mathrm{R}^{2}$ & Within $=0.303$ & & Within $=0.290$ & & Within $=0.073$ & \\
\hline & Overall $=0.157$ & & Overall $=0.093$ & & Overall $=0.041$ & \\
\hline
\end{tabular}


Table 4 Regressions results by admission type for acute and acute internal medicine hospital admissions for those 80 years and older 2010-2014, including municipal fixed effects and with MAU services interactions (log-log models)

\begin{tabular}{|c|c|c|c|c|c|c|c|c|}
\hline \multirow[b]{2}{*}{ Variables } & \multicolumn{2}{|l|}{ Acute } & \multicolumn{2}{|l|}{ Acute internal medicine } & \multicolumn{2}{|l|}{ Acute } & \multicolumn{2}{|l|}{ Acute internal medicine } \\
\hline & Estimate (95\% Cl) & p Value & Estimate (95\% Cl) & p Value & Estimate (95\% Cl) & p Value & Estimate (95\% Cl) & p Value \\
\hline Population aged $80+$ years & $0.866(0.67$ to 1.06$)$ & 0.00 & $0.836(0.64$ to 1.04$)$ & 0.00 & $0.849(0.65$ to 1.05$)$ & 0.00 & $0.815(0.61$ to 1.02$)$ & 0.00 \\
\hline Death rate & $0.082(0.03$ to 0.14$)$ & 0.00 & 0.077 (0.02 to 0.13$)$ & 0.01 & $0.073(0.02$ to 0.13$)$ & 0.01 & 0.069 (0.01 to 0.12$)$ & 0.02 \\
\hline Nursing home beds & $0.001(-0.07$ to 0.07$)$ & 0.98 & $0.006(-0.07$ to 0.08$)$ & 0.87 & $0.005(-0.07$ to 0.08$)$ & 0.89 & $0.008(-0.06$ to 0.08$)$ & 0.83 \\
\hline GPs & $0.030(-0.14$ to 0.20$)$ & 0.73 & $0.049(-0.11$ to 0.21$)$ & 0.56 & $0.041(-0.13$ to 0.21$)$ & 0.63 & $0.052(-0.11$ to 0.21$)$ & 0.52 \\
\hline GPs man-years & $-0.190(-0.59$ to 0.21$)$ & 0.35 & $-0.238(-0.63$ to 0.15$)$ & 0.23 & $-0.158(-0.51$ to 0.20$)$ & 0.38 & $-0.192(-0.53$ to 0.15$)$ & 0.26 \\
\hline Total population & $0.301(-0.03$ to 0.63$)$ & 0.07 & $0.314(-0.00$ to 0.63$)$ & 0.05 & $0.235(-0.10$ to 0.57$)$ & 0.17 & $0.247(-0.07$ to 0.56$)$ & 0.13 \\
\hline Any MAU access & $-0.017(-0.03$ to -0.01$)$ & 0.01 & $-0.016(-0.03$ to -0.00$)$ & 0.01 & & & & \\
\hline Host with LES and $24 / 7$ & & & & & $-0.032(-0.09$ to 0.02$)$ & 0.24 & $-0.040(-0.10$ to 0.02$)$ & 0.17 \\
\hline Host with doctor $24 / 7$ & & & & & $-0.081(-0.11$ to -0.05$)$ & 0.00 & $-0.086(-0.12$ to -0.05$)$ & 0.00 \\
\hline Host with only LES & & & & & $-0.002(-0.05$ to 0.04$)$ & 0.92 & $-0.003(-0.05$ to 0.04$)$ & 0.90 \\
\hline Host without LES or doc & & & & & $-0.009(-0.03$ to 0.01$)$ & 0.33 & $-0.006(-0.03$ to 0.01$)$ & 0.52 \\
\hline \multicolumn{9}{|l|}{$24 / 7$} \\
\hline Visitor with LES and $24 / 7$ & & & & & $-0.038(-0.06$ to -0.01$)$ & 0.00 & $-0.040(-0.07$ to -0.01$)$ & 0.00 \\
\hline Visitor with doc $24 / 7$ & & & & & $-0.066(-0.12$ to -0.01$)$ & 0.02 & $-0.065(-0.12$ to -0.01$)$ & 0.02 \\
\hline Visitor with LES & & & & & $-0.045(-0.07$ to -0.02$)$ & 0.00 & $-0.039(-0.07$ to -0.01$)$ & 0.00 \\
\hline Visitor without ED or doc & & & & & $-0.007(-0.04$ to 0.03$)$ & 0.67 & $0.002(-0.03$ to 0.04$)$ & 0.90 \\
\hline \multicolumn{9}{|l|}{$24 / 7$} \\
\hline Alone with LES and $24 / 7$ & & & & & $0.010(-0.01$ to 0.03$)$ & 0.33 & $0.006(-0.02$ to 0.03$)$ & 0.62 \\
\hline Alone with only $24 / 7$ & & & & & $-0.017(-0.03$ to -0.00$)$ & 0.03 & $-0.017(-0.03$ to -0.00$)$ & 0.02 \\
\hline Alone with only LES & & & & & $-0.048(-0.12$ to 0.02$)$ & 0.20 & $-0.045(-0.12$ to 0.03$)$ & 0.26 \\
\hline $\begin{array}{l}\text { Alone without LES or doctor } \\
24 / 7\end{array}$ & & & & & $0.022(-0.02$ to 0.06$)$ & 0.26 & $0.021(-0.02$ to 0.06$)$ & 0.28 \\
\hline constant & $-3.516(-5.35$ to -1.68$)$ & 0.00 & $-3.553(-5.32$ to -1.78$)$ & 0.00 & $-3.202(-5.03$ to -1.37$)$ & 0.00 & $-3.217(-4.98$ to -1.46$)$ & 0.00 \\
\hline Observations & 16106 & & 16106 & & 16106 & & 16106 & \\
\hline \multirow[t]{2}{*}{$\mathrm{R}^{2}$} & Within $=0.066$ & & Within=0.062 & & Within $=0.070$ & & Within $=0.067$ & \\
\hline & Overall $=0.102$ & & Overall $=0.090$ & & Overall $=0.133$ & & Overall $=0.117$ & \\
\hline
\end{tabular}

GP, general practitioner; LES, local emergency service; MAU, municipal acute bed unit. 
were not co-located with emergency services generally had no effect on the admission rates.

The demand variables yielded reasonable effects. Increase in the share of population with higher age groups was associated with increased admission rates, as was increase in the death rates, reflecting a higher use of hospitals at life's end. ${ }^{10-12}{ }^{19}$ Supply side variables had weaker effects, which is also consistent with previous studies. ${ }^{20}$

Our sensitivity analyses indicated that significant effects of MAUs can mainly be found in medium-tolarge municipalities. We speculate that demographic and geographic characteristics of smaller, often more remote municipalities have led to the development and usage of services and provisions substituting and complementing hospital care in these areas prior to the introduction of the MAU mandate- a factor not captured by the fixed effects nor the factors controlled for by the selection of independent variables.

\section{Strengths and weaknesses}

To the best of our knowledge, this study is the first to explicitly capture the effect of an intermediate care alternative on general hospital admissions. The major strength of this study was the exact starting dates and implementation range of MAUs over the study period making it uniquely possible to isolate the effects of MAUs on the number of hospital admissions. Unlike other studies that have focused on outcomes and patient satisfaction, this study has clearly shown a significant impact of intermediate care alternatives on hospital admission rates.

There are several caveats to consider when evaluating our results. An important limitation is the narrow time period after the reform's implementation and lack of $50 \%$ of the municipalities yet to adopt MAU services. A more extensive analysis can be completed from 2016 and thereafter, when, in theory, every municipality will have implemented MAU access. The unknown number and composition of patients in MAUs is an additional limitation. Therefore, as stated in the analysis, linear regression models were applied to estimate the effects of introducing MAUs relative to the reduction in demand for hospital services without MAU patient volume data.

Prior to being mandated, introduction of MAUs by the municipalities occurred via self-selection, which raises possible concerns with regard to endogeneity affecting generalisability. Fixed effects reduce the problems by allowing us to compare effects over time within the same units. However, the results may not be generalisable to municipalities that have not yet opted to introduce MAUs.

Another possible endogeneity concern occurs from municipalities expecting demand for hospital admissions to rise, introducing MAU services, and this introduction subsequently prevents noticing the rise in figures, ultimately biasing the estimates of the effect towards zero. A national push for preventing or finding alternatives to hospital admissions, including introducing intermediate care (MAUs) at a time when a rise in demand was expected, also biases estimates towards zero. Potentially biasing the estimates towards zero, the only influence these possible sources of endogeneity have on our findings is underestimation of the effects.

The analyses of the 'catch-up' effects indicated that municipalities with the highest admission rates in 2011 would have the highest effect of implementation of the MAUs. Yet this did not influence or change the overall findings from the analyses reported above.

\section{CONCLUSIONS AND POLICY IMPLICATIONS}

The specification outlining the implementation of MAUs within the Norwegian Coordination Reform was established with the expectation that intermediate care would promote more suitable and ultimately more costeffective healthcare solutions to acute specialist care, particularly for the elderly. Our findings emphasise the likelihood of important gains in reducing hospital admissions through implementation of intermediate care health policies. Consistencies in our results suggest that intermediate care, like that of MAUs, is a step towards alleviating the burden on hospital care capacity by reducing admission volume.

Further examinations of the total number of bed days, including both bed days in MAUs and hospitals, and cost-effectiveness analyses, comparing hospitalisation and MAU treatment, would add valuable input to determining the overall success of intermediate care initiatives. Additional valuable input could include outcome variables describing the health status of the patients. Analysing hospital admissions for those municipalities that have had MAU-like community hospital services since the 1980s, as well as other small, typically remote municipal areas with intermediate services prior to the reform, could also add important perspectives to the issue. Investigating relational effects of MAUs compared with the introduction of new or additional nursing home beds is also of highly relevant interest.

Contributors TPH conceptualised and designed the study, as well as contributed to the background. JOS analysed the data and drafted the manuscript. Both authors reviewed drafts of the article.

Funding The paper is funded by the Norwegian Research Council through the evaluation programme for the Cooperation reform (NFR grant 220764 -'Prosessevaluering av Samhandlingsreformen: Statlige virkemidler, kommunale innovasjoner').

Competing interests None declared

Ethics approval Granted by the Regional Ethics Committee South-East, Norway; and the Norwegian Data Inspectorate.

Provenance and peer review Not commissioned; externally peer reviewed.

Data sharing statement Access to the restricted data can be sought from the Regional Committees for Medical and Health Research Ethics, South-East Norway; and the Norwegian Data Inspectorate.

Open Access This is an Open Access article distributed in accordance with the Creative Commons Attribution Non Commercial (CC BY-NC 4.0) license, which permits others to distribute, remix, adapt, build upon this work non- 
commercially, and license their derivative works on different terms, provided the original work is properly cited and the use is non-commercial. See: http:// creativecommons.org/licenses/by-nc/4.0/

\section{REFERENCES}

1. Kmietowicz Z. Small hospitals could help to bolster community services, says NHS chief. BMJ 2014;348:g3662.

2. West D. Simon Stevens' first interview: parts of the NHS must be 'completely reinvented'. Health Service Journal, 2014

3. Helsedirektoratet. Kommunenes plikt til øyeblikkelig hjelp døgnopphold. Veiledningsmateriell, 2014. [Directorate of Health 2014. Municipalities' obligation for acute bed units: Guidance Material. Revised 2/2014. Oslo: Norwegian Directorate of Health.]

4. Ringard Å, Sagan A, Sperre Saunes I, et al. Norway: health system review. Health Syst Transit 2013;15:270-321.

5. Lappegard O, Hjortdahl P. The choice of alternatives to acute hospitalization: a descriptive study from Hallingdal, Norway. BMC Fam Pract 2013;14:87.

6. Aaraas I. The Finnmark general practitioner hospital study. Patient characteristics, patient flow and alternative care level. Scand J Prim Health Care 1995;13:250-6.

7. Young J, Green J, Forster A, et al. Postacute care for older people in community hospitals: a multicenter randomized, controlled trial. J Am Geriatr Soc 2007;55:1995-2002.

8. Dahl U, Johnsen R, Sætre R, et al. The influence of an intermediate care hospital on health care utilization among elderly patients-a retrospective comparative cohort study. BMC Health Serv Res 2015;15:48.

9. Timmer AJ, Unsworth CA, Taylor NF. Rehabilitation interventions with deconditioned older adults following an acute hospital admission: a systematic review. Clin Rehabil 2014;28: 1078-86.

10. Felder S, Meier M, Schmitt $\mathrm{H}$. Health care expenditure in the last months of life. J Health Econ 2000;19:679-95.

11. Zweifel P, Felder S, Meiers M. Ageing of population and health care expenditure: a red herring? Health Econ 1999;8:485-96.

12. Zweifel P, Felder S, Werblow A. Population ageing and health care expenditure: new evidence on the "Red Herring". Geneva Pap Risk Insur Issues Pract 2004;29:652-66.

13. Rattso J. Local-government allocation of labor and the grant system -an applied-model analysis of local-government behavior in Norway. Environ Plann C 1989;7:273-84.

14. Inman RP. The fiscal performance of local governments: an interpretative review. In: Mieszkowski P, Straszheim M, eds. Current issues in urban economics. Baltimore: The John Hopkins University Press, 1979

15. Rubinfeld DL. The economics of the local public sector. In: Auerbach AJ, Feldstein M, eds. Handbook of public economics. Amsterdam: Elsevier Science Publisher (North-Holland), 1987:571-645.

16. Wooldridge JM. Econometric analysis of cross section and panel data. 2nd edn. MIT Press, 2010.

17. Allison PD. Fixed effects regression methods for longitudinal data using SAS. SAS Institute, 2005.

18. Dranove D, Cone K. Do state rate setting regulations really lower hospital expenses? J Health Econ 1985;4:159-65.

19. Hakkinen U, Martikainen $P$, Noro A, et al. Aging, health expenditure, proximity to death, and income in Finland. Health Econ Policy $L$ 2008;3:165-95.

20. Beales S, Smith PC. The role of primary health care in controlling the cost of specialist health care. Nord Econ Policy Rev 2012;2:153-86 